Journal of Social Sciences 3 (3): 151-154, 2007

ISSN 1549-3652

(C) 2007 Science Publications

\title{
An Analysis of Death Using the National Longitudinal Mortality Study
}

\author{
Mark Gius \\ Quinnipiac University, Hamden, CT
}

\begin{abstract}
Using an expansive survey of death that includes not only socioeconomic and demographic information on a deceased person, but also his or her cause of death, the present study attempts to examine the determinants of death. The present study uses the National Longitudinal Mortality Study, Public Use File (NMLS), which contains data on 370,930 individuals over the age of 24, 41,554 of whom are dead. Results suggest that men are more likely to die from all six examined causes of death. In addition, race appears to play a significant role in mortality and, by implication, access to quality health care. Income, however, only plays a role in mortality for those diseases where treatment and/or recovery may be lengthy and thus expensive.
\end{abstract}

Key words: Mortality, death, economics

\section{INTRODUCTION}

Death is a certainty of life. The cause of one's demise, however, is subject to uncertainty due to a mix of genetic, environmental and lifestyle factors that determine the actual reason for a person's death. For example, a person may smoke cigarettes for his entire life and then be struck down in his prime by the crosstown bus. An athletic, health-conscious non-smoker may contract and die from lung cancer; witness the recent passing of Dana Reeves, the wife of Christopher Reeves. Hence, although death will come to all of us, the means of our passing is heavily subject to random events. Given the above, it may be interesting to statistically examine the primary causes of death. Using an expansive survey of death that includes socioeconomic and demographic information on the deceased in addition to his or her cause of death, the present study attempts to examine the causes of death.

There has been a plethora of research on the determinants of mortality. Unfortunately, most of it focused on less-developed countries or comparisons between mortality rates for developed and lessdeveloped countries ${ }^{[1,2,3]}$. An excellent survey on the topic of mortality recently appeared in the Journal of Economic Perspectives ${ }^{[4]}$. Another comprehensive examination of mortality was conducted by Rogers, Hummer and Nam ${ }^{[5]}$.

In looking at mortality within countries, both studies noted that several factors stand out as the primary determinants of death; they are education level, income and race. Well-educated individuals are less likely to engage in risky, health damaging behaviors such as smoking and drinking heavily. Well-educated individuals are also more likely to have jobs that are rather safe and that do not expose them to injurious risks. African-Americans, who have less access to quality health care, are more likely to die at younger ages. Finally, lower-income individuals have less access to quality health care and hence are also more likely to succumb to diseases.

\section{MATERIALS AND METHODS}

In order to examine the determinants of mortality, six causes of death are examined: infection; cancer; Diabetes; social causes, which includes cirrhosis of the liver, traffic accidents and suicides; cardiovascular diseases; and respiratory diseases. This is the same categorical breakdown of diseases used by Rogers, Hummer and $\mathrm{Nam}^{[5]}$. Using prior research as a guide, the following equation is estimated for each cause of death:

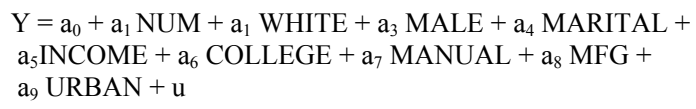

where Y takes the value of one if the person died of the cause under consideration and it takes the value of zero if the person died of something else, NUM is the number of people in the individual's household, WHITE is one if person is Caucasian and zero

Corresponding Author: Mark Gius, Ph.D., Department of Economics, Quinnipiac University, Hamden, CT 06518. 
otherwise, MALE is one if person is male and zero otherwise, MARITAL is one if person is married and zero otherwise, INCOME equals one if a person's income is greater than $\$ 50,000$ and zero otherwise, COLLEGE equals one if person graduated from college and zero otherwise, MANUAL equals one if person has an occupation that involves manual labor, MFG equals one if person had a job in the manufacturing sector and URBAN is one if person lived in urban area. Only persons at least 25 years of age are examined in the present study.

Theory and anecdotal evidence suggest that NUM, WHITE, INCOME, MARITAL and COLLEGE should all have negative effects on mortality, while MALE, MANUAL, MFG and URBAN should have positive effects. The greater NUM implies that the individual has access to a network of family friends, whose support may assist in the recovery from certain diseases. WHITE should be negative, indicating that whites, due to perceived and actual racism, may have better access to health care professionals, preventive care and adequate diets. INCOME is negative because it is assumed that more income can buy an individual better health care, regardless of genetic or environmental factors. COLLEGE is negative suggesting that well-educated individuals are more likely to be aware of the necessary lifestyle choices that must be made in order to prevent certain diseases from occurring.

MALE is positive since men are more prone to certain diseases and afflictions such as heart disease. MFG and MANUAL are positive since it is assumed the individuals working in manufacturing and especially individuals engaged in manual labor, are more likely to be injured on the job and less likely to seek medical assistance when necessary. Finally, URBAN is negative since it is assumed that urban environments are naturally less healthy, given pollution and the greater likelihood of violent crime.

All data used in the present study was obtained from the National Longitudinal Mortality Study, Public Use File (NMLS). This database is a random sample of the non-institutionalized population of the United States and consists of data from the Current Population Surveys, Annual Social and Economic supplements and the 1980 Census. This socioeconomic data is combined with death certificate information to obtain cause of death information. The Public Use File contains data on 370,930 individuals over the age of 24, 41,554 of which are dead. Unfortunately, the Public Use File does not contain information on the dates of the data. All that is known is that the observations were collected from March 1973 to March 2002.
The cause of death is reported from the individual's death certificate. The coding used is the International Classification of Diseases (ICD), which is published by the World Health Organization. The six causes of death and corresponding ICD codes are as follows: infection (008-139); cancer (140-239); diabetes (250); social causes (571, 800-999); cardiovascular diseases (390-459); and respiratory diseases (460-519). Since the dependent variable is binary, equation (1) is estimated using a logit regression function.

\section{RESULTS}

Descriptive statistics are presented on Table 1. Regression results are presented on Tables 2-7. As the results suggest, MALE is the only explanatory variable that is significant and positive for all six causes of death. NUM, COLLEGE and MFG are significant and negative for all six causes of death. Hence, collegeeducated women in the manufacturing sector are less likely to die of the diseases examined in the present study.

WHITE is significant and negative in all of the regressions except in the cardiovascular and respiratory regressions where it is significant and positive. MARITAL is significant and negative for all diseases except cancer, for which it is significant and positive. INCOME is significant and negative for cancer, cardiovascular and respiratory. MANUAL is significant and negative for all diseases except social causes. Finally, URBAN is significant and positive for infection.

These results suggest that race plays a significant role in mortality and, by implication, access to quality health care. Apparently, whites have much better access to health care than do individuals from other races. INCOME only plays a role in mortality for those diseases where treatment and/or recovery may be lengthy and thus expensive.

Although most of the results confirm theory and the results of prior studies, two results were unexpected. Both MFG and MANUAL were significant and negative for most diseases. It was assumed earlier that both of these variables would have positive effects on mortality. One possible reason why these two variables may have negative effects on mortality is that unions and the better health care benefits that unions typically obtain for their members, are much more prevalent in the manufacturing sector and in the manual labor occupations. Hence, given that they have better access to health care, these individuals may be less likely to die from diseases and illness than others even though 
J. Social Sci., 3 (3): 151-154, 2007

Table 1: Descriptive Statistics

\begin{tabular}{ll}
\hline $\mathrm{N}=370,930$ & Mean \\
Variable & 0.0015 \\
Y=Infection & 0.028 \\
Y=Cancer & 0.0067 \\
Y=Social Causes & 0.002 \\
Y=Diabetes & 0.055 \\
Y=Cardiovascular & 0.0086 \\
Y=Respiratory & 47.8 \\
Age & 3.1 \\
NUM & 0.88 \\
WHITE & 0.47 \\
MALE & 0.71 \\
MARITAL & 0.043 \\
INCOME & 0.17 \\
COLLEGE & 0.23 \\
MANUAL & 0.14 \\
MFG & 0.66 \\
URBAN &
\end{tabular}

Table 2: Infection regression

\begin{tabular}{lcc}
\hline Variable & Coefficient & Test Statistic \\
\hline Intercept & -5.283 & -32.07 \\
NUM & -0.23 & -6.48 \\
WHITE & -0.51 & -4.56 \\
MALE & 0.82 & 9.03 \\
MARITAL & -0.74 & -7.62 \\
INCOME & -0.26 & -0.88 \\
COLLEGE & -0.81 & -5.55 \\
MANUAL & -0.97 & -6.32 \\
MFG & -0.99 & -4.41 \\
URBAN & 0.259 & 2.58 \\
\hline & & \\
Table 3: Cancer regression & & \\
\hline Variable & Coefficient & Test Statistic \\
\hline Intercept & -2.58 & -61.27 \\
NUM & -0.37 & -40.25 \\
WHITE & -0.112 & -3.56 \\
MALE & 0.57 & 27.07 \\
MARITAL & 0.182 & 7.64 \\
INCOME & -0.122 & -2.05 \\
COLLEGE & -0.833 & -24.33 \\
MANUAL & -0.627 & -20.13 \\
MFG & -0.395 & -10.3 \\
URBAN & 0.03 & 1.67 \\
\hline & & \\
Table 4: Diabetes regression & & -33.87 \\
\hline Variable & Coefficient & Test Statistic \\
\hline Intercept & -4.688 & -9.81 \\
NUM & -0.316 & -4.71 \\
WHITE & -0.46 & -1.84 \\
MALE & 0.328 & -0.77 \\
MARITAL & -0.152 & -7.37 \\
INCOME & -0.181 & -7.40 \\
COLLEGE & -0.992 & -3.63 \\
MANUAL & -1.008 & 0.94 \\
MFG & -0.61 & \\
URBAN & 0.076 & \\
\hline & & \\
& & \\
\hline
\end{tabular}

Table 5: Social causes regression

\begin{tabular}{lcc}
\hline Variable & Coefficient & Test Statistic \\
\hline Intercept & -4.54 & -55.92 \\
NUM & -0.126 & -8.35 \\
WHITE & -0.293 & -5.11 \\
MALE & 1.07 & 23.20 \\
MARITAL & -0.477 & -10.48 \\
INCOME & -0.158 & -1.27 \\
COLLEGE & -0.665 & -9.79 \\
MANUAL & -0.067 & -1.30 \\
MFG & -0.408 & -5.99 \\
URBAN & 0.016 & 0.37 \\
\hline & & \\
Table 6: Cardiovascular regression & \\
\hline Variable & Coefficient & Test Statistic \\
\hline Intercept & -1.59 & -50.45 \\
NUM & -0.415 & -58.68 \\
WHITE & 0.108 & 4.43 \\
MALE & 0.711 & 45.84 \\
MARITAL & -0.299 & -17.64 \\
INCOME & -0.39 & -7.52 \\
COLLEGE & -1.19 & -43.26 \\
MANUAL & -1.08 & -41.58 \\
MFG & -0.777 & -22.72 \\
URBAN & -0.019 & -1.22 \\
\hline & & \\
Table 7: Respiratory regression & & -47.2 \\
\hline Variable & Coefficient & Test Statistic \\
\hline Intercept & -3.86 & -23.71 \\
NUM & -0.434 & -4.68 \\
WHITE & 0.33 & -4.86 \\
MALE & 0.965 & -17.82 \\
MARITAL & -0.202 & -19.11 \\
INCOME & -0.525 & -0.13 \\
COLLEGE & -1.23 & \\
MANUAL & -1.32 & -10.73 \\
MFG-1.06 & -0.005 & \\
URBAN & & \\
\hline & & \\
\hline
\end{tabular}

their occupations or industrial status may actually expose them to greater environmental harm and the possibility of injury.

\section{DISCUSSION}

Using an expansive survey of death that includes socioeconomic and demographic information on the deceased in addition to his or her cause of death, the present study attempted to examine the causes of death. Although there has been a plethora of research on the determinants of mortality, most of it focuses on lessdeveloped countries or comparisons between mortality rates for developed and less-developed countries. The present study used the National Longitudinal Mortality Study, Public Use File (NMLS), which contains data on 
370,930 individuals over the age of $24,41,554$ of whom are dead.

Results suggested that MALE is significant and positive for all six causes of death, while NUM, COLLEGE and MFG are significant and negative for all six causes of death. Hence, college-educated women in the manufacturing sector are less likely to die of the diseases examined in the present study. In addition, race appears to play a significant role in mortality and, by implication, access to quality health care. INCOME, however, only plays a role in mortality for those diseases where treatment and/or recovery may be lengthy and thus expensive.

\section{REFERENCES}

1. Cutler, David, Angus Deaton and Adriana LlerasMuney, 2006. The Determinants of Mortality. J. Econ. Perspectives, 20: 97-120.
2. Kunst, A. and J. Mackenbach, 1994. The Size of Mortality Differences Associated With Educational Level in Nine Industrialized Countries. Am. J. Public Health, 84: 932-937.

3. Kwon, Soonman, 2003. Health and Health Care. Soc. Indicators Res., 62: 171-178.

4. Rogers, Richard, Robert Hummer and Charles Nam, 1995. Living and Dying in the USA. San Diego, Academic Press.

5. Rodgers, G. 2002, Income and Inequality as Determinants of Mortality: An International CrossSection Analysis. Inter. J. Epidemiology, 31: 533538. 